\title{
Semi Markov Approach for Asymptotic Performance Analysis of a Standby System with Server Failure
}

\author{
R.K. Bhardwaj, Ph. D. \\ Department of Statistics, \\ Punjabi University Patiala \\ Pin -147002, India
}

\author{
Ravinder Singh, R. Scholar \\ Department of Statistics, \\ Punjabi University Patiala \\ Pin -147002, India
}

\begin{abstract}
In this paper the asymptotic performance of a cold standby system with two identical units is analyzed. When a unit fails it is inspected by a server to check the feasibility of repair or replacement. If repair is not feasible, unit is replaced by new. The server is subjected to failure while performing its job. The system model is developed using semi-Markov approach of Markov processes. The regenerative point technique is used to derive expressions for various measures of system performance. The random variables associated with the system (failure time, inspection time, repair time, treatment time) are assumed to follow arbitrary distribution with different probability density functions. A numerical study is also presented to demonstrate the practical importance of the research.
\end{abstract}

\section{General Terms}

Stochastic Modeling, Reliability Analysis

\section{Keywords}

Asymptotic, Standby, semi-Markov Approach, Arbitrary distribution, Server failure

\section{INTRODUCTION}

The satisfactory performance of a system (or product) has always been a subject of major concern for both manufacturer and user. The performance of any entity is normally assessed with either its ability to perform its intended function without failure for given time interval under stated conditions or how long it is available for use. The high reliability and availability is always desired. The redundancy techniques are proven effective tools for enhancing system's reliability and availability and thus gained more attention in system studies. Being practically more important among all redundancy techniques the one, in which the spare is kept in cold standby mode, has been extensively studied by various scholars in the literature. Osaki and Nakagawa [10], Mahmoud and Moshref [9], El-Said and El-Sherbeny [4] have stochastically analyzed two-unit cold standby systems with different failure and repair strategies. Bhardwaj and Malik [2] asymptotically analyzed the performance of a cold standby system with constrained repair and arbitrary distributed inspection time.

Most of the studies, in the literature, have taken only the failure of units in to account. Despite of the fact that in a repairable system the role of the service facility/ server is highly important, not too much work has been done concerning server failure. The failure of service facility during operation may cause adverse consequences both in terms of declined reliability as well as availability and thus the profit of the system. Though, Malik et al. [8] discussed a system model with server failure and unit replacement at different failure modes, followed by inspection but they completely ignored the importance of redundancy as is needed in many critical systems like nuclear power plants, remote sensing, communication satellites etc. Moreover, in many studies, such as Leung et al. [7], Ke et al. [6], Bao and Cui [1], the failure and repair times of units are assumed to follow, ridiculously, the exponential distribution. But it is not reasonable for each and every situation. Rather, we should use suitable distribution in accordance with prevailing situation.

Therefore, keeping the practical significance in mind, in this paper a probabilistic model is developed for a two unit repairable standby system. The system consists of two identical units, initially one unit is operative and other is kept as cold standby. Upon failure, the failed unit goes under inspection for examining the feasibility of repair and if repair is not viable it is replaced by new unit. A single server available in the system performs the tasks of inspection, repair and replacement. During task operation the server may fail and directly goes under treatment upon failure. It is assumed that all repairs and treatments are perfect i.e. after repair of the unit and treatment of server they perform as new one. Omitting the ambiguity of using exponential distribution, it is assumed that the random variables associated with failure, inspection, repair, replacement time of units and treatment time of server are statistically independent and each follows general distribution with different probability density function. The model is developed using semi-Markov theory (Ibe, [5]) and re-generative point technique is used to derive the expressions for different measures of system performance, such as transition probabilities, MTSF, availability, busy period, expected number of inspections, replacements, server treatments and profit incurred to the system. To demonstrate the practical importance of the study the numerical results are obtained, for a particular case, using Laplace and Inverse Laplace Transforms (Davies, [3]).

\section{NOTATIONS}

$$
\begin{array}{ll}
\mathrm{O} & : \text { The unit is operative and in normal mode. } \\
\mathrm{CS} & : \text { The unit is kept as cold standby. } \\
\mathrm{SG} & : \text { The server is good. } \\
\mathrm{FU}_{\mathrm{r}} / \mathrm{FU}_{\mathrm{R}} & : \text { The unit is under repair/ under repair } \\
\text { continuously from previous state. }
\end{array}
$$

$\mathrm{FU}_{\mathrm{i}} / \mathrm{FU}_{\mathrm{I}} \quad$ : The unit is under inspection/ under inspection continuously from previous state.

$\mathrm{SFU}_{\mathrm{t} /} \mathrm{SFU}_{\mathrm{T}} \quad$ : The server is failed and under treatment/ under treatment continuously from previous state.

$\mathrm{FW}_{\mathrm{r}} / \mathrm{FW}_{\mathrm{R}}$. The unit is failed and waiting for repair/ waiting for repair continuously from previous state. 
$\mathrm{FW}_{\mathrm{i}} / \mathrm{FW}_{\mathrm{I}} \quad$ : The unit is failed and waiting for inspection/ waiting for inspection continuously From previous state

$\mathrm{z}(\mathrm{t}) / \mathrm{Z}(\mathrm{t}) \quad: \quad \mathrm{pdf} / \mathrm{cdf}$ of failure rate of the unit.

$\mathrm{u}(\mathrm{t}) / \mathrm{U}(\mathrm{t}) \quad$ : pdf / cdf of failure rate of the server.

$\mathrm{g}(\mathrm{t}) / \mathrm{G}(\mathrm{t}) \quad$ : pdf / cdf of repair time of the failed unit.

$\mathrm{h}(\mathrm{t}) / \mathrm{H}(\mathrm{t}) \quad:$ pdf / cdf of the treatment time of the server.

$\mathrm{m}(\mathrm{t}) / \mathrm{M}(\mathrm{t}) \quad$ : pdf / cdf of inspection time of the failed unit.

p/q : Probability that repair of the unit at failure is not feasible/ feasible.

$\mathrm{q}_{\mathrm{ij}}(\mathrm{t}) / \mathrm{Q}_{\mathrm{ij}}(\mathrm{t}) \quad$ : pdf / cdf of direct transition time from a regenerative state $S_{i}$ to a regenerative state $S_{j}$ without visiting any other regenerative state.

$\mathrm{M}_{\mathrm{i}}(\mathrm{t}) \quad:$ Probability that the system is up initially in state $S_{\mathrm{i}} \in \mathrm{E}$ is up at time $\mathrm{t}$ without visiting to any other regenerative state.

$\mathrm{W}_{\mathrm{i}}(\mathrm{t}) \quad$ : Probability that the server is busy in the state $S_{i}$ upto time ' $t$ ' without makin any transition to any other regenerative state or returning to the same state via one or more non-regenerative states.

(S) / (C) Laplace convolution.

: Symbol for Stieltjes convolution /

$\sim$ /* : Symbol for Laplace Stieltjes

Transform(LST) / Laplace Transform(LT).

'(desh) : Symbol for derivative of the function

$\mathrm{q}_{\mathrm{ij} . \mathrm{k}}(\mathrm{t}) / \mathrm{Q}_{\mathrm{ij} . \mathrm{k}}(\mathrm{t}) \quad$ : pdf / cdf of first passage time from a regenerative state $S_{i}$ to a regenerative state $S_{j}$ or to a failed state $S_{j}$ visiting state $S_{k}$ once in $(0, t]$.

$\mathrm{q}_{\mathrm{ij} . \mathrm{kr}}(\mathrm{t}) / \mathrm{Q}_{\mathrm{ij} . \mathrm{kr}}(\mathrm{t}) \quad$ : $\mathrm{pdf} / \mathrm{cdf}$ of first passage time from regenerative state $S_{i}$ to a regenerative state $S_{j}$ or to a failed state $S_{j}$ visiting state $S_{k}, S_{r}$ once in $(0, t]$.

$\mathrm{q}_{\mathrm{iij} . \mathrm{krs}}(\mathrm{t}) / \mathrm{Q}_{\mathrm{ij} . \mathrm{krs}}(\mathrm{t})$ : pdf / cdf of first passage time from regenerative state $S_{i}$ to a regenerative state $S_{j}$ or to a failed state $S_{j}$ visiting state $S_{k}, S_{r}$ and $S_{s}$ once in $(0, t]$.

The following are the possible states of the system model fig. 1 .

The regenerative states:

$$
\begin{aligned}
& S_{0}=(0, C S, S G), S_{1}=\left(F_{i}, 0, S G\right), \\
& S_{2}=\left(F W_{i}, 0, S F U_{t}\right), S_{3}=\left(F_{r}, 0, S G\right), \\
& S_{4}=\left(F W_{r}, 0, S F U_{t}\right)
\end{aligned}
$$

Here it can be stated that all the entrance points of state $\mathrm{S}_{\mathrm{i}}, i=0,1,2,3,4$ are re-generative points.

Non-regenerative states:

$$
\begin{gathered}
\mathrm{S}_{5}=\left(\mathrm{FU}_{\mathrm{I}}, \mathrm{FW}_{\mathrm{i}}, \mathrm{SG}\right), \quad \mathrm{S}_{6}=\left(\mathrm{FW}_{\mathrm{i}}, \mathrm{FW}_{\mathrm{I}}, \mathrm{SFU}_{\mathrm{t}}\right), \\
\mathrm{S}_{7}=\left(\mathrm{FW}_{\mathrm{I}}, \mathrm{FW}_{\mathrm{i}}, \mathrm{SFU}_{\mathrm{T}}\right), \mathrm{S}_{8}=\left(\mathrm{FU}_{\mathrm{i}}, \mathrm{FW}_{\mathrm{I}}, \mathrm{SG}\right), \\
\mathrm{S}_{9}=\left(\mathrm{FU}_{\mathrm{R}}, \mathrm{FW}_{\mathrm{i}}, \mathrm{SG}\right), \mathrm{S}_{10}=\left(\mathrm{FW}_{\mathrm{r}}, \mathrm{FW}_{\mathrm{I}}, \mathrm{SFU}_{\mathrm{t}}\right) \\
\mathrm{S}_{11}=\left(\mathrm{FU}_{\mathrm{r}}, \mathrm{FW}_{\mathrm{I}}, \mathrm{SG}\right), \quad \mathrm{S}_{12}=\left(\mathrm{FW}_{\mathrm{R}}, \mathrm{FW}_{\mathrm{i}}, \mathrm{SFU}_{\mathrm{T}}\right),
\end{gathered}
$$

\section{PERFORMANCE ANALYSIS}

\subsection{Transition Probabilities}

Simple probabilistic considerations yields the following expressions for the non- zero elements

$$
\mathrm{p}_{\mathrm{ij}}=\mathrm{Q}_{\mathrm{ij}}(\infty)=\int_{0}^{\infty} \mathrm{q}_{\mathrm{ij}}(\mathrm{t})
$$

we get

$$
\begin{aligned}
& \mathrm{p}_{01}=\int_{0}^{\infty} \mathrm{z}(\mathrm{t}) \mathrm{dt}, \quad \mathrm{p}_{10}=\int_{0}^{\infty} \mathrm{pm}(\mathrm{t}) \overline{\mathrm{Z}}(\mathrm{t}) \overline{\mathrm{U}}(\mathrm{t}) \mathrm{dt}, \\
& \mathrm{p}_{12}=\int_{0}^{\infty} \mathrm{u}(\mathrm{t}) \overline{\mathrm{Z}}(\mathrm{t}) \overline{\mathrm{M}}(\mathrm{t}) \mathrm{dt}, \mathrm{p}_{13}=\int_{0}^{\infty} \mathrm{qm}(\mathrm{t}) \overline{\mathrm{U}}(\mathrm{t}) \overline{\mathrm{Z}}(\mathrm{t}) \mathrm{dt}, \\
& \mathrm{p}_{15}=\int_{0}^{\infty} \mathrm{z}(\mathrm{t}) \overline{\mathrm{M}}(\mathrm{t}) \overline{\mathrm{U}}(\mathrm{t}) \mathrm{dt}, \quad \mathrm{p}_{11.5}=\mathrm{p}_{1,5} @ \mathrm{p}_{5,1} \\
& \mathrm{p}_{11.5,11}=\mathrm{p}_{1,5} @ \mathrm{p}_{5,11} @ \mathrm{p}_{11,1} \text {, } \\
& \mathrm{p}_{11.5(68)^{\mathrm{n}}}=\mathrm{p}_{1,5} \Subset \mathrm{p}_{5,6} \Subset \mathrm{p}_{6,8} @ \mathrm{p}_{8,1} \text {, }
\end{aligned}
$$

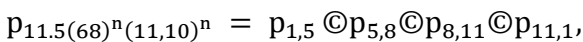

$$
\begin{aligned}
& \mathrm{p}_{21}=\int_{0}^{\infty} \mathrm{h}(\mathrm{t}) \overline{\mathrm{Z}}(\mathrm{t}) \mathrm{dt}, \mathrm{p}_{27}=\int_{0}^{\infty} \mathrm{z}(\mathrm{t}) \overline{\mathrm{H}}(\mathrm{t}) \mathrm{dt},
\end{aligned}
$$

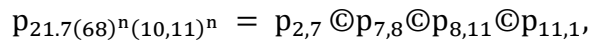

$$
\begin{aligned}
& \mathrm{p}_{21.7,8}=\mathrm{p}_{2,7} @ \mathrm{p}_{7,8} @ \mathrm{p}_{8,1}, \quad \mathrm{p}_{31}=\int_{0}^{\infty} \mathrm{g}(\mathrm{t}) \overline{\mathrm{Z}}(\mathrm{t}) \overline{\mathrm{U}}(\mathrm{t}) \mathrm{dt}, \\
& \mathrm{p}_{34}=\int_{0}^{\infty} \mathrm{u}(\mathrm{t}) \overline{\mathrm{Z}}(\mathrm{t}) \overline{\mathrm{G}}(\mathrm{t}) \mathrm{dt}, \mathrm{p}_{39}=\int_{0}^{\infty} \mathrm{z}(\mathrm{t}) \overline{\mathrm{Z}}(\mathrm{t}) \overline{\mathrm{G}}(\mathrm{t}) \mathrm{dt}, \\
& \mathrm{p}_{31.9,(10,11)^{\mathrm{n}}}=\mathrm{p}_{3,9} @ \mathrm{p}_{9,10} @ \mathrm{p}_{10,11} @ \mathrm{p}_{11,1} \text { ， } \\
& \mathrm{p}_{43}=\int_{0}^{\infty} \mathrm{h}(\mathrm{t}) \overline{\mathrm{Z}}(\mathrm{t}) \mathrm{dt}, \mathrm{p}_{4,12}=\int_{0}^{\infty} \mathrm{z}(\mathrm{t}) \overline{\mathrm{H}}(\mathrm{t}) \mathrm{dt} \text {, } \\
& \mathrm{p}_{41.12,(10,11)^{\mathrm{n}}}=\mathrm{p}_{4,12} @ \mathrm{p}_{12,11} @ \mathrm{p}_{11,1} \\
& \mathrm{p}_{56}=\int_{0}^{\infty} \mathrm{u}(\mathrm{t}) \overline{\mathrm{M}}(\mathrm{t}) \mathrm{dt}, \mathrm{p}_{5,11}=\int_{0}^{\infty} \mathrm{qm}(\mathrm{t}) \overline{\mathrm{U}}(\mathrm{t}) \mathrm{dt} \\
& \mathrm{p}_{68}=\int_{0}^{\infty} \mathrm{h}(\mathrm{t}) \mathrm{dt}, \mathrm{p}_{78}=\int_{0}^{\infty} \mathrm{h}(\mathrm{t}) \mathrm{dt} \text {, } \\
& \mathrm{p}_{8,1}=\int_{0}^{\infty} \mathrm{pm}(\mathrm{t}) \overline{\mathrm{U}}(\mathrm{t}) \mathrm{dt}, \mathrm{p}_{86}=\int_{0}^{\infty} \mathrm{u}(\mathrm{t}) \overline{\mathrm{M}}(\mathrm{t}) \mathrm{dt}, \\
& \mathrm{p}_{8,11}=\int_{0}^{\infty} \mathrm{qm}(\mathrm{t}) \overline{\mathrm{U}}(\mathrm{t}) \mathrm{dt}, \mathrm{p}_{9,10}=\int_{0}^{\infty} \mathrm{u}(\mathrm{t}) \mathrm{dt} \\
& p_{10,11}=\int_{0}^{\infty} h(t) d t, \quad p_{11,1}=\int_{0}^{\infty} g(t) \bar{U}(t) d t, \\
& \mathrm{p}_{11,10}=\int_{0}^{\infty} \mathrm{u}(\mathrm{t}) \overline{\mathrm{G}}(\mathrm{t}) \mathrm{dt}, \mathrm{p}_{12,11}=\int_{0}^{\infty} \mathrm{h}(\mathrm{t}) \mathrm{dt},
\end{aligned}
$$

For these Transition Probabilities, it can be verified that

$$
\begin{aligned}
& \mathrm{p}_{01}=\mathrm{p}_{10}+\mathrm{p}_{12}+\mathrm{p}_{13}+\mathrm{p}_{15}=\mathrm{p}_{10}+\mathrm{p}_{12}+\mathrm{p}_{13}+ \\
& \mathrm{p}_{11.5}+\mathrm{p}_{11.5,11}+\mathrm{p}_{11.5,(6,8)^{\mathrm{n}}}+\mathrm{p}_{11.5(68)^{\mathrm{n}}(10,11)^{\mathrm{n}}} \\
& =\mathrm{p}_{21}+\mathrm{p}_{27}=\mathrm{p}_{21}+\mathrm{p}_{21.7(68)^{\mathrm{n}}}+\mathrm{p}_{21.7,(6,8)^{\mathrm{n}}(10,11)^{\mathrm{n}}} \\
& =p_{31}+p_{34}+p_{39}=p_{31}+p_{34}+p_{31.9,(10,11)^{n}}
\end{aligned}
$$

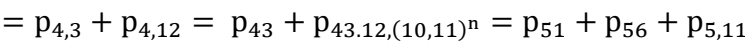

$$
\begin{aligned}
& =p_{6,8}=p_{7,8}=p_{8,1}+p_{8,6}+p_{8,11}=p_{9,10}=p_{10,11} \\
& =\mathrm{p}_{11,1}+\mathrm{p}_{11,10}=\mathrm{p}_{12,11}=1
\end{aligned}
$$




\subsection{Mean Sojourn Times}

The Mean sojourn time $\mu_{\mathrm{i}}$ in state $S_{\mathrm{i}}$ are given by:

$$
\begin{gathered}
\mu_{0}=\int_{0}^{\infty} \overline{\mathrm{Z}}(\mathrm{t}) \mathrm{dt}, \mu_{1}=\int_{0}^{\infty} \overline{\mathrm{Z}}(\mathrm{t}) \overline{\mathrm{U}}(\mathrm{t}) \overline{\mathrm{M}}(\mathrm{t}) \mathrm{dt}, \\
\mu_{2}=\int_{0}^{\infty} \overline{\mathrm{H}}(\mathrm{t}) \overline{\mathrm{Z}}(\mathrm{t}) \mathrm{dt}, \mu_{3}=\int_{0}^{\infty} \overline{\mathrm{Z}}(\mathrm{t}) \overline{\mathrm{U}}(\mathrm{t}) \overline{\mathrm{G}}(\mathrm{t}) \mathrm{dt}, \\
\mu_{4}=\int_{0}^{\infty} \overline{\mathrm{H}}(\mathrm{t}) \overline{\mathrm{Z}}(\mathrm{t}) \mathrm{dt}
\end{gathered}
$$

The unconditional mean time taken by the system to transit from any state $S_{i}$ when time is counted from epoch at entrance into state $S_{\mathrm{j}}$ is stated as:

And

$$
\mathrm{m}_{\mathrm{ij}}=\int \mathrm{td} \mathrm{Q}_{\mathrm{ij}}(\mathrm{t})=-\mathrm{q}_{\mathrm{ij}}^{*^{\prime}}(0)
$$

$$
\begin{aligned}
& \mathrm{m}_{01}=\mu_{0}, \mathrm{~m}_{10}+\mathrm{m}_{12}+\mathrm{m}_{13}+\mathrm{m}_{15}=\mu_{1} \\
& m_{10}+m_{12}+m_{13}+m_{11.5}+m_{11.5,11}+m_{11.5,(6,8)^{n}}=\mu_{1}^{\prime} \text {, }
\end{aligned}
$$

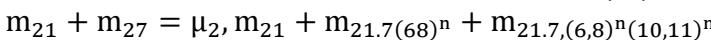

$$
\begin{aligned}
& =\mu_{2}^{\prime}, \mathrm{m}_{31}+\mathrm{m}_{34}+\mathrm{m}_{39}=\mu_{3}, \mathrm{~m}_{31}+\mathrm{m}_{34}+\mathrm{m}_{31.9,(10,11)^{\mathrm{n}}}
\end{aligned}
$$

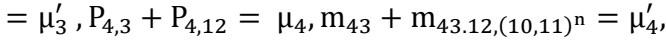

$$
\begin{aligned}
& \mathrm{m}_{51}+\mathrm{m}_{56}+\mathrm{m}_{5,11}=\mu_{5}, \mathrm{~m}_{6,8}=\mu_{6}, \mathrm{~m}_{7,8}=\mu_{7}, \\
& m_{8,1}+m_{8,6}+m_{8,11}=\mu_{8}, m_{9,10}=\mu_{9}, m_{10,11}=\mu_{10} \text {, } \\
& \mathrm{m}_{11,1}+\mathrm{m}_{11,10}=\mu_{11}, \mathrm{~m}_{12,11}=\mu_{12}
\end{aligned}
$$

\subsection{Mean Time to System Failure}

Let $\emptyset_{\mathrm{i}}(\mathrm{t})$ be the c.d.f of the first passage time from regenerative state $\mathrm{Si}$ to a failed state. Regarding the failed state as absorbing state, we have the following recursive relations for $\emptyset_{\mathrm{i}}(\mathrm{t})$ :

$\emptyset_{i}(t)=\sum_{j} Q_{i, j}(t)(S) \emptyset_{j}(t)+\sum_{k} Q_{i, k}(t) i=0,1,2,3,4$

Where $\mathrm{Sj}$ is an un-failed regenerative state to which the given regenerative state $\mathrm{Si}$ can transit and $\mathrm{Sk}$ is failed state to which the state $\mathrm{Si}$ can transit directly.

Taking LST of equation (3) and solving for $\widetilde{\emptyset}_{\mathrm{o}}(\mathrm{s})$, we have

$$
\mathrm{R}^{*}(\mathrm{~s})=\frac{1-\widetilde{\emptyset}_{\mathrm{o}}(\mathrm{s})}{\mathrm{s}}
$$

The reliability $R(t)$ can be obtained by taking inverse Laplace transition of (4) and MTSF is given by

$$
\operatorname{MTSF}(\mathrm{T})=\lim _{\mathrm{s} \rightarrow 0} \mathrm{R}^{*}(\mathrm{~s})=\frac{\left\{1-\widetilde{\emptyset}_{\mathrm{o}}(\mathrm{s})\right\}}{\mathrm{s}}
$$

$T=$

$\mu_{0}\left[1-p_{13} p_{31}-p_{12} p_{21}-p_{43} p_{34}+p_{34} p_{43} p_{12} p_{21}\right]+\left[\mu_{1}+\mu_{2} p_{12}\right]\left[1-p_{34} p_{43}\right]$ $+\left[\mu_{3}+\mu_{4} \mathrm{P}_{34}\right] \mathrm{P}_{13}$

\section{COST ANALYSIS}

\subsection{Steady State Availability}

Let $A_{i}(t)$ be the probability that the system is in up-state at an instant ' $t$ ' given that the system entered regenerative state $S_{i}$ at $t=0$. The recursive relations for $A_{i}(t)$ are as follows:

$$
A_{i}(t)=M_{i}(t)+\sum_{j} q_{i, j}^{(n)}(t) \subseteq A_{j}(t) \quad i=0,1,2,3,4
$$

Where $S_{j}$ is any successive regenerative state to which the regenerative state $\mathrm{S}_{\mathrm{i}}$ can transit through $\mathrm{n}$ transitions. $M_{i}(t)$ is the probability that the system is up initially in state $S_{i} \in E$ is up at time $\mathrm{t}$ without visiting to any other regenerative state, we have

$$
M_{0}(t)=\int_{0}^{\infty} \bar{Z}(t) d t, M_{1}(t)=\int_{0}^{\infty} \bar{M}(t) \bar{Z}(t) \bar{U}(t) d t,
$$

$$
\begin{gathered}
M_{2}(t)=\int_{0}^{\infty} \bar{H}(t) \bar{Z}(t) d t \\
M_{3}(t)=\int_{0}^{\infty} \bar{G}(t) \bar{Z}(t) \bar{U}(t) d t, M_{4}(t)=\int_{0}^{\infty} \bar{H}(t) \bar{Z}(t) d t
\end{gathered}
$$

Taking LT of equation (7) and solving for $\mathrm{A}_{0}^{*}(\mathrm{~s})$, the steady state availability is given by

$\mathrm{A}_{0}(\infty)$

$=\operatorname{lims}_{\mathrm{s} \rightarrow 0} \mathrm{~A}_{0}^{*}(\mathrm{~s})$

$=\frac{\left(\mu_{0} p_{10}+\mu_{1}+\mu_{2} p_{12}\right)\left(1-p_{34} p_{43}\right)+\left(\mu_{3}+p_{34} \mu_{4}\right) p_{13}}{\left(\mu_{0} p_{10}+\mu_{1}^{\prime}+\mu_{2}^{\prime} p_{12}\right)\left(1-p_{34} p_{43}\right)+\left(\mu_{3}^{\prime}+p_{34} \mu_{4}^{\prime}\right) p_{13}}$

\subsection{Busy Period Analysis for the Server}

Let $B_{i}(t)$ be the probability that the server is busy in repair of the unit at an instant $t$ given that the system entered regenerative state $S_{i}$ at $t=0$. The recursive relations for $B_{i}(t)$ are as follows:

$$
\mathrm{B}_{\mathrm{i}}(\mathrm{t})=\mathrm{W}_{\mathrm{i}}(\mathrm{t})+\sum_{j} \mathrm{q}_{\mathrm{i}, \mathrm{j}}^{(\mathrm{n})}(\mathrm{t}) \subseteq \mathrm{B}_{\mathrm{j}}(\mathrm{t}) \mathrm{i}=0,1,2
$$

where $S_{j}$ is any successive regenerative state to which the regenerative state $S_{\mathrm{i}}$ can transit through $\mathrm{n}$ transitions. $W_{i}(t)$ be the probability that the server is busy in state $S_{i}$ due to repair of the unit up to time ' $t$ ' without making any transition to any other regenerative state or returning to the same via one or more non-regenerative state and so

$$
\begin{aligned}
& =\bar{M}(t) \bar{Z}(t) \bar{U}(t)+(z(t) \bar{M}(t) \bar{U}(t) \mathbb{C} 1) \bar{M}(t) \\
& +(z(t) \bar{M}(t) \bar{U}(t) \mathbb{C} u(t) \bar{M}(t) \mathbb{C} 1) \bar{H}(t) \\
& +(z(t) \bar{M}(t) \bar{U}(t) \Subset u(t) \bar{M}(t) \Subset h(t) \Subset 1) \bar{M}(t) \\
& W_{3}=\bar{G}(t) \bar{U}(t) \bar{Z}(t)+(z(t) \bar{U}(t) \bar{G}(t) \Subset 1) \bar{U}(t) \\
& +(z(t) \bar{U}(t) \bar{G}(t) @ u(t)(1) \bar{H}(t) \\
& +(z(t) \bar{U}(t) \bar{G}(t) \Subset u(t) \Subset h(t) \Subset 1) \bar{G}(t)
\end{aligned}
$$

Using LT, of equation (9) and solving for $\mathrm{B}_{0}^{*}(\mathrm{~s})$, the time for which server is busy due to repair of unit is given by $\mathrm{B}_{0}=\operatorname{lims}_{\mathrm{s} \rightarrow 0} \mathrm{~B}_{0}^{*}(\mathrm{~s})$

$$
=\frac{\mathrm{W}_{1}^{*}(0)\left(1-\mathrm{p}_{34} \mathrm{p}_{43}\right)+\mathrm{W}_{3}^{*}(0) \mathrm{p}_{13}}{\left(\mu_{0} \mathrm{p}_{10}+\mu_{1}^{\prime}+\mu_{2}^{\prime} \mathrm{p}_{12}\right)\left(1-\mathrm{p}_{34} \mathrm{p}_{43}\right)+\left(\mu_{3}^{\prime}+\mathrm{p}_{34} \mu_{4}^{\prime}\right) \mathrm{p}_{13}}
$$

\subsection{Expected Number of Inspections by \\ the Server}

Let $I_{i}(t)$ be the expected number of inspections by the server in $(0, t]$ given that the system entered regenerative state $S_{i}$ at $t=0$. The recursive relations for $I_{i}(t)$ are as follow:

$$
\mathrm{I}_{\mathrm{i}}(\mathrm{t})=\sum_{\mathrm{j}} \mathrm{Q}_{\mathrm{i}, \mathrm{j}}(\mathrm{t})(\mathrm{S})\left[\delta_{\mathrm{j}}+\mathrm{I}_{\mathrm{j}}(\mathrm{t})\right] \mathrm{i}=0,1,2,3,4
$$

Where $S_{j}$ is any regenerative state to which the given regenerative state $\mathrm{S}_{\mathrm{i}}$ transits and $\delta_{j}=1$, if $\mathrm{S}_{\mathrm{j}}$ is the regenerative state where the server does the job afresh, otherwise $\delta_{j}=0$.

Using LT, of equation (11) and solving for $\widetilde{\mathrm{I}_{0}}(\mathrm{~s})$, the expected number of inspections by the server are given by

$$
\begin{aligned}
& \mathrm{I}_{0}=\operatorname{lims}_{\mathrm{s} \rightarrow 0} \tilde{\mathrm{I}_{0}}(\mathrm{~s}) \\
& =\frac{\left[\mathrm{p}_{12}+\mathrm{p}_{12}+\mathrm{p}_{13}\right]\left[1-\mathrm{p}_{34} \mathrm{p}_{43}\right]}{\left(\mu_{0} \mathrm{p}_{10}+\mu_{1}^{\prime}+\mu_{2}^{\prime} \mathrm{p}_{12}\right)\left(1-\mathrm{p}_{34} \mathrm{p}_{43}\right)+\left(\mu_{3}^{\prime}+\mathrm{p}_{34} \mu_{4}^{\prime}\right) \mathrm{p}_{13}}
\end{aligned}
$$

\subsection{Expected Number of Treatment}

\section{Given To the Server}

Let $T_{i}(t)$ be the expected number of treatments given to the server in $(0, t]$ given that the system entered regenerative state $\mathrm{S}_{\mathrm{i}}$ at $\mathrm{t}=0$. The recursive relations for $\mathrm{T}_{\mathrm{i}}(\mathrm{t})$ are as follow: 
$\mathrm{T}_{\mathrm{i}}(\mathrm{t})=\sum_{\mathrm{j}} \mathrm{Q}_{\mathrm{i}, \mathrm{j}}(\mathrm{t})(\mathrm{S})\left[\delta_{\mathrm{j}}+\mathrm{T}_{\mathrm{j}}(\mathrm{t})\right] \mathrm{i}=0,1,2,3,4$

Where $S_{j}$ is any regenerative state to which the given regenerative state $\mathrm{S}_{\mathrm{i}}$ transits and $\delta_{j}=1$, if $\mathrm{S}_{\mathrm{j}}$ is the regenerative state where the server does the job afresh, otherwise $\delta_{j}=0$.

Using LT, of equation (13) and solving for $\widetilde{\mathrm{T}_{0}}(\mathrm{~s})$, the expected number of the treatments given to the server are given by $\mathrm{T}_{0}=\lim _{\mathrm{s} \rightarrow 0} \widetilde{\mathrm{T}_{0}}(\mathrm{~s})$

$=\frac{\mathrm{p}_{12}\left[1-\mathrm{p}_{34} \mathrm{p}_{43}\right]+\mathrm{p}_{13} \mathrm{p}_{34}}{\left(\mu_{0} \mathrm{p}_{10}+\mu_{1}^{\prime}+\mu_{2}^{\prime} \mathrm{p}_{12}\right)\left(1-\mathrm{p}_{34} \mathrm{p}_{43}\right)+\left(\mu_{3}^{\prime}+\mathrm{p}_{34} \mu_{4}^{\prime}\right) \mathrm{p}_{13}}$

\subsection{Expected Number of Server Visits}

Let $\mathrm{N}_{\mathrm{i}}(\mathrm{t})$ be the expected number of visits by the server in $(0, \mathrm{t}]$ given that the system entered regenerative state $S_{i}$ at $t=0$. The recursive relations for $\mathrm{N}_{\mathrm{i}}(\mathrm{t})$ are as follows:

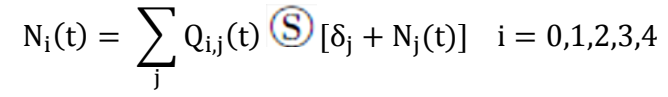

where $S_{j}$ is any regenerative state to which the given regenerative state $\mathrm{S}_{\mathrm{i}}$ transits and $\delta_{j}=1$, if $\mathrm{S}_{\mathrm{j}}$ is the regenerative state where the server does the job afresh, otherwise $\delta_{j}=0$.

Using LT, of equation (15) and solving for $\widetilde{\mathrm{N}_{0}}(\mathrm{~s})$, the expected number of visits by the server are given by

$$
\begin{aligned}
& \mathrm{N}_{0}=\lim _{\mathrm{s} \rightarrow 0} \mathrm{~s} \widetilde{\mathrm{N}_{0}}(\mathrm{~s}) \\
& =\frac{\left(\mathrm{p}_{10}+\mathrm{p}_{12}\right)\left(1-\mathrm{p}_{34} \mathrm{p}_{43}\right)+\mathrm{p}_{34} \mathrm{p}_{13}}{\left(\mu_{0} \mathrm{p}_{10}+\mu_{1}^{\prime}+\mu_{2}^{\prime} \mathrm{p}_{12}\right)\left(1-\mathrm{p}_{34} \mathrm{p}_{43}\right)+\left(\mu_{3}^{\prime}+\mathrm{p}_{34} \mu_{4}^{\prime}\right) \mathrm{p}_{13}}
\end{aligned}
$$

\subsection{Expected Number of Replacement of}

\section{the Unit}

Let $R_{i}(t)$ be the expected number of replacements of the unit in $(0, t]$ given that the system entered regenerative state $S_{i}$ at $t=0$. The recursive relations for $R_{i}(t)$ are as follow:

$$
\mathrm{R}_{\mathrm{i}}(\mathrm{t})=\sum_{\mathrm{j}} \mathrm{Q}_{\mathrm{i}, \mathrm{j}}(\mathrm{t})(\mathrm{S})\left[\delta_{j}+\mathrm{R}_{\mathrm{j}}(\mathrm{t})\right] \mathrm{i}=0,1,2,3,4
$$

Where $S_{j}$ is any regenerative state to which the given regenerative state $\mathrm{S}_{\mathrm{i}}$ transits and $\delta_{j}=1$, if $\mathrm{S}_{\mathrm{j}}$ is the regenerative state where the server does the job afresh, otherwise $\delta_{j}=0$.

Using LT, of equation (17) and solving for $\widetilde{\mathrm{R}_{0}}(\mathrm{~s})$, the expected number of visits by the server are given by

$$
\begin{aligned}
& \mathrm{R}_{0}=\lim _{\mathrm{s} \rightarrow 0} \mathrm{~S} \widetilde{\mathrm{R}_{0}}(\mathrm{~s}) \\
& =\frac{\left(1-\mathrm{p}_{43} \mathrm{p}_{34}\right)\left(\mathrm{p}_{10}+\mathrm{p}_{12} \mathrm{p}_{21.7,8}\right)}{\left(\mu_{0} \mathrm{p}_{10}+\mu_{1}^{\prime}+\mu_{2}^{\prime} \mathrm{p}_{12}\right)\left(1-\mathrm{p}_{34} \mathrm{p}_{43}\right)+\left(\mu_{3}^{\prime}+\mathrm{p}_{34} \mu_{4}^{\prime}\right) \mathrm{p}_{13}}
\end{aligned}
$$

\subsection{PROFIT ANALYSIS}

Let $X_{i}(t)$ denote the measure of $i^{\text {th }}$ characteristic of the system in $(0, t]$ and $K_{i}$ be its coefficient then the profit incurred to the system model in $(0, t]$ is given by

$\mathrm{P}(\mathrm{t})=K_{0} A_{0}(\mathrm{t})-\sum_{\mathrm{i}=1}^{5} \mathrm{C}_{\mathrm{i}} \mathrm{X}_{\mathrm{i}}(\mathrm{t})$

Asymptotically $\left(\right.$ i.e.t $\left.t_{\rightarrow \infty}\right)$, we have

$$
\begin{aligned}
\text { Profit, } \mathrm{P}_{0}=\operatorname{Lim}_{\mathrm{t} \rightarrow \infty} \mathrm{P}(\mathrm{t}) & =\operatorname{Lim}_{\mathrm{t} \rightarrow \infty}\left[K_{0} A_{0}(\mathrm{t})-\sum_{\mathrm{i}=1}^{5} \mathrm{C}_{\mathrm{i}}\left\{\mathrm{X}_{\mathrm{i}}(\mathrm{t})\right\}\right] \\
= & K_{0} A_{0}-\sum_{\mathrm{i}=1}^{5} \mathrm{C}_{\mathrm{i}}\left\{\mathrm{X}_{\mathrm{i}}(\infty)\right\}
\end{aligned}
$$

Where,

$$
X_{i}(\infty)=\left\{\begin{array}{l}
B_{0} ; \text { for } i=1 \\
I_{0} ; \text { for } i=2 \\
T_{0} ; \text { for } i=3 \\
\mathrm{~N}_{0} ; \text { for } \mathrm{i}=4 \\
\mathrm{R}_{0} ; \text { for } \mathrm{i}=5
\end{array}\right.
$$

$\mathrm{K}_{0}=$ Revenueperunituptimeofthesystem.

$\mathrm{C}_{1}=$ Cost per unit timefor which server is busy.

$C_{2}=$ Cost per unit time for the inspections of the unit

$\mathrm{C}_{3}=$ Cost per unit time treatment given to the server.

$\mathrm{C}_{4}=$ Cost per unit visit by the server.

$C_{5}=$ Cost per unit time for the replacement of the uint And $\mathrm{A}_{0}, \mathrm{~B}_{0}, \mathrm{I}_{0}, \mathrm{~T}_{0}, \mathrm{~N}_{0}, \mathrm{R}_{0}$ are already defined.

\section{NUMERICAL STUDY}

Let us suppose that all the random variables follow exponential distribution with different parameters i.e. $z(t)=\lambda e^{-\lambda t}, g(t)=\alpha e^{-\alpha t}, u(t)=\gamma e^{-\gamma t}, \quad h(t)=$ $\beta e^{-\beta t}, m(t)=\delta e^{-\delta t}$.

For demonstration purpose, numerical results for various measures of system performance are obtained by assigning hypothetical values to different parameters. Initially, we take $\lambda=0.1, \alpha=0.5, \gamma=0.3, \delta=1.2, \mathrm{p}=0.4, \mathrm{q}=0.6$ and then the values of one or two parameters are varied at a time and the change patterns of system characteristics are observed. Table I, II and III represent, respectively, the behavior of mean time to system failure, availability and profit. It can be observed that all the measures exhibit upward trend with increasing server treatment rate $(\beta)$, unit's repair rate $(\alpha)$ and inspection rate $(\delta)$. This trend persists even when the values of $\mathrm{p}$ and $\mathrm{q}$ are interchanged. The values of these measures decline with increasing unit failure rate $(\lambda)$ and server failure rate $(\gamma)$. Further, the effect of unit failure rate $(\lambda)$ is quicker on MTSF then other parameters 
Table I: MTSF performance with varying server treatment rate

\begin{tabular}{|c|c|c|c|c|c|c|}
\hline \multirow{2}{*}{$\begin{array}{c}\text { Treatment Rate } \\
(\beta)\end{array}$} & \multicolumn{6}{|c|}{ MTSF $(\lambda=0.1, \alpha=0.5, \gamma=0.3, \delta=1.2, p=0.4, q=0.6)$} \\
\hline & $\lambda=0.1$ & $\lambda=0.3$ & $\alpha=0.6$ & $\gamma=0.5$ & $\delta=1.5$ & $\mathrm{p}=0.6$ \\
\hline 1 & 37.55928 & 14.89796 & 38.9519 & 35.5992 & 39.36224 & 40.34532 \\
\hline 1.1 & 37.84387 & 14.96196 & 39.26644 & 35.96659 & 39.67213 & 40.66869 \\
\hline 1.2 & 38.09278 & 15.01838 & 39.54158 & 36.29294 & 39.94318 & 40.95154 \\
\hline 1.3 & 38.31235 & 15.06849 & 39.78429 & 36.58477 & 40.18227 & 41.20104 \\
\hline 1.4 & 38.50746 & 15.1133 & 40 & 36.84729 & 40.39474 & 41.42276 \\
\hline 1.5 & 38.682 & 15.1536 & 40.19297 & 37.08471 & 40.5848 & 41.6211 \\
\hline 1.6 & 38.83905 & 15.19004 & 40.36661 & 37.30047 & 40.75581 & 41.79957 \\
\hline 1.7 & 38.98112 & 15.22315 & 40.5237 & 37.4974 & 40.91052 & 41.96101 \\
\hline 1.8 & 39.11025 & 15.25337 & 40.66649 & 37.67787 & 41.05114 & 42.10776 \\
\hline 1.9 & 39.22814 & 15.28107 & 40.79685 & 37.84387 & 41.17951 & 42.24172 \\
\hline
\end{tabular}

Table II: Availability performance with varying server treatment rate

\begin{tabular}{|c|c|c|c|c|c|c|}
\hline \multirow{2}{*}{$\begin{array}{c}\text { Treatment Rate } \\
(\boldsymbol{\beta})\end{array}$} & \multicolumn{6}{|c|}{ Availability $(\lambda=0.1, \alpha=0.5, \gamma=0.3, \delta=1.2, p=0.4, q=0.6)$} \\
\hline & $\lambda=0.1$ & $\lambda=\mathbf{0 . 3}$ & $\alpha=0.6$ & $\gamma=0.5$ & $\delta=1.5$ & $\mathrm{p}=0.6$ \\
\hline 1 & 0.91352 & 0.808539 & 0.933716 & 0.871874 & 0.939754 & 0.95626 \\
\hline 1.1 & 0.914446 & 0.810186 & 0.934692 & 0.873394 & 0.940774 & 0.957033 \\
\hline 1.2 & 0.915307 & 0.811732 & 0.935595 & 0.874806 & 0.941714 & 0.95774 \\
\hline 1.3 & 0.916103 & 0.813175 & 0.936426 & 0.876112 & 0.942579 & 0.958387 \\
\hline 1.4 & 0.916837 & 0.814519 & 0.93719 & 0.877318 & 0.943373 & 0.958978 \\
\hline 1.5 & 0.917514 & 0.815769 & 0.937893 & 0.878431 & 0.944102 & 0.959518 \\
\hline 1.6 & 0.918138 & 0.816933 & 0.93854 & 0.87946 & 0.944773 & 0.960014 \\
\hline 1.7 & 0.918715 & 0.818017 & 0.939136 & 0.880412 & 0.945391 & 0.960469 \\
\hline 1.8 & 0.919248 & 0.819027 & 0.939687 & 0.881294 & 0.945961 & 0.960888 \\
\hline 1.9 & 0.919742 & 0.81997 & 0.940197 & 0.882113 & 0.946489 & 0.961274 \\
\hline
\end{tabular}

Table III: Profit performance with varying server treatment rate

\begin{tabular}{|c|c|c|c|c|c|c|}
\hline \multirow{2}{*}{$\begin{array}{c}\text { Treatment Rate } \\
(\beta)\end{array}$} & \multicolumn{6}{|c|}{ Profit $(\lambda=0.1, \alpha=0.5, \gamma=0.3, \delta=1.2, p=0.4, q=0.6)$} \\
\hline & $\lambda=0.1$ & $\lambda=0.3$ & $\alpha=0.6$ & $\gamma=0.5$ & $\delta=1.5$ & $p=0.6$ \\
\hline 1 & 17945.99 & 15779.88 & 18351.61 & 17104.93 & 18472.67 & 18866.45 \\
\hline 1.1 & 17962.05 & 15809.9 & 18368.86 & 17131.33 & 18490.68 & 18880.62 \\
\hline 1.2 & 17977.12 & 15838.18 & 18384.91 & 17156.03 & 18507.4 & 18893.65 \\
\hline 1.3 & 17991.12 & 15864.65 & 18399.77 & 17179 & 18522.84 & 18905.59 \\
\hline 1.4 & 18004.1 & 15889.37 & 18413.48 & 17200.3 & 18537.07 & 18916.53 \\
\hline 1.5 & 18016.11 & 15912.41 & 18426.12 & 17220.03 & 18550.18 & 18926.55 \\
\hline 1.6 & 18027.22 & 15933.88 & 18437.78 & 17238.31 & 18562.27 & 18935.75 \\
\hline 1.7 & 18037.5 & 15953.9 & 18448.56 & 17255.25 & 18573.42 & 18944.21 \\
\hline 1.8 & 18047.04 & 15972.59 & 18458.53 & 17270.99 & 18583.74 & 18952.01 \\
\hline 1.9 & 18055.89 & 15990.05 & 18467.77 & 17285.62 & 18593.3 & 18959.21 \\
\hline
\end{tabular}

\section{CONCLUSION}

A cold standby system consisting of two identical units and a single server (service facility) has been studied. The server is assumed to fail while performing job activity. The system model has been developed using the theory of semi-Markov processes and the regenerative point technique of renewal theory is used to drive expressions for various measures of system performance. The numerical results obtained, for a particular case, emphasized on the practical importance of the study. Further, under the set framework, the study indicates that a two unit cold standby repairable system can be made more reliable and profitable by employing a server of high inspection and repair rates.

Moreover, if the server fails during operation then its treatment must be ensured at a higher rate.

The system model developed in this paper can be implemented by system designers, technocrats and business planners to achieve the objectives of high reliability and enhanced system performances. 


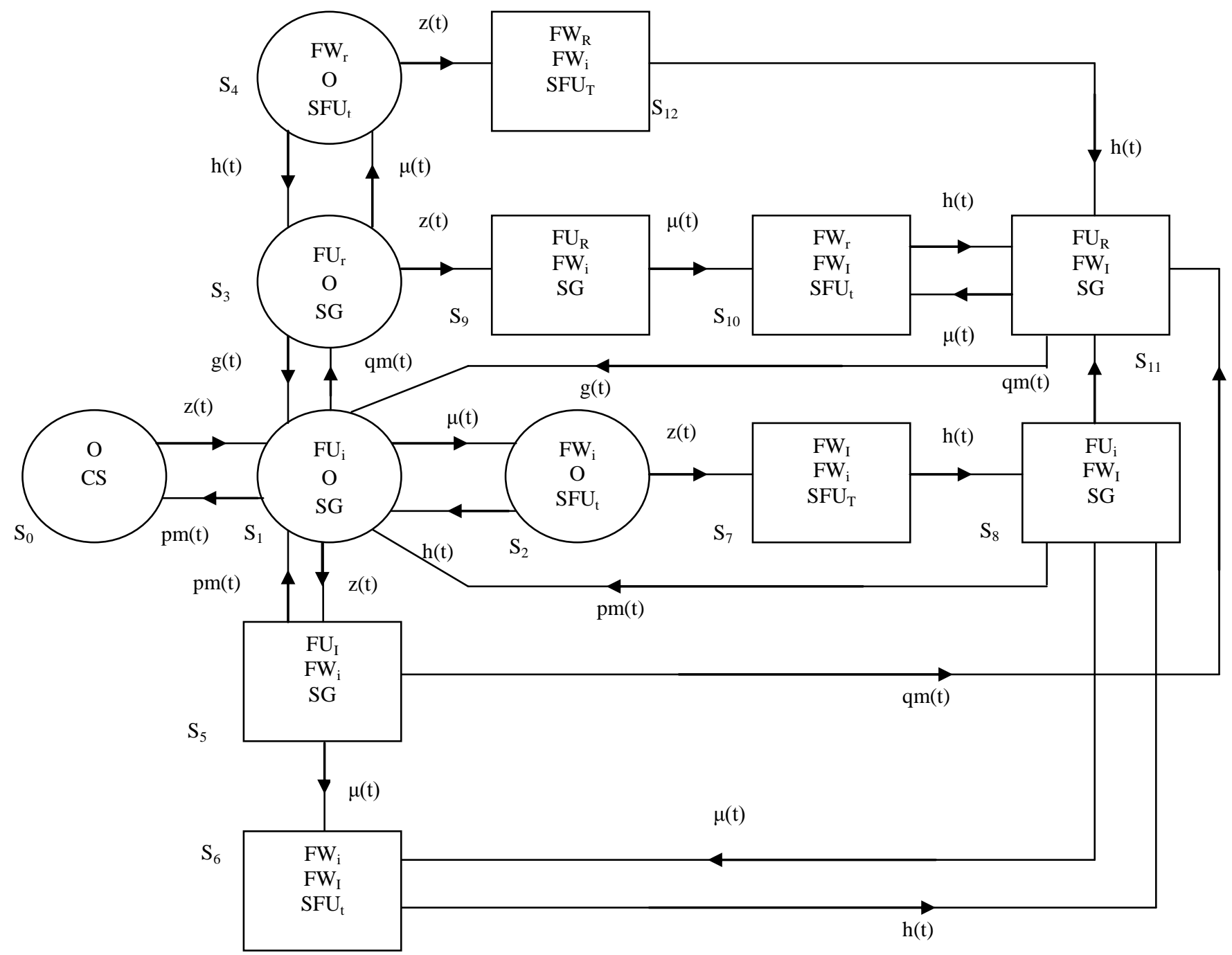

Fig 1: System Schematic Diagram

\section{ACKNOWLEDGMENTS}

The authors are thankful to the anonymous referees and the Editor for their valuable comments which have helped to improve the presentation of this paper.

This paper is a part of research project F.N. 42-34/2013(SR) financially supported by HRD Ministry, Government of India under Major Research Project scheme of University Grants Commission (UGC).

\section{REFRENCES}

[1] Bao, Xinzhuo, and Lirong Cui. "A study on reliability for a two-item cold standby Markov repairable system with neglected failures." Communications in Statistics-Theory and Methods 41.21 (2012): 3988-3999.

[2] Bhardwaj, R. K., and Malik, S. C. Asymptotic performance analysis of 2003 cold standby system with constrained repair and arbitrary distributed inspection time. International Journal of Applied Engineering Research 6, 08 (2011), 1493-1502.

[3] Davies, B. Integral transforms and their applications, vol. 41. Springer, 2002.

[4] El-Said, K. M., and El-Sherbeny, M. S. Stochastic analysis of a two-unit cold standby system with twostage repair and waiting time. Sankhya B 72, 1 (2010), 110.
[5] Ibe, Oliver C. Markov processes for stochastic processes, Elsevier Academic Press, USA (2009).

[6] Ke, Jyh-Bin, Jyh-Wei Chen, and Kuo-Hsiung Wang. "Reliability measures of a repairable system with standby switching failures and reboot delay." Quality Technology \& Quantitative Management 8.1 (2011): 15-26.

[7] Leung, Kit Nam Francis, Yuan Lin Zhang, and Kin Keung Lai. "Analysis for a two-dissimilar-component cold standby repairable system with repair priority." Reliability Engineering \& System Safety 96.11 (2011): 1542-1551.

[8] Malik, S.C., Dhankar, A.K. and Kumar, Ashish. "CostBenefit Analysis of a System with Server Failure and Replacement of the Unit at Different Failure Modes Subject to Inspection". International Journal of Computer Applications 47(1), (2012), 27-33.

[9] Mahmoud, M.A.W. and Moshref, M.E., Probabilistic analysis of a two unit cold standby redundant system subject to failure of controlled device. Microelectron. Reliab. Vol. 37 (4) (1997), 623-628.

[10] Osaki, S., and Nakagawa, T. On a two-unit standby redundant system with standby failure. Operations Research 19, 2 (1971), 510-523. 